\title{
Solar-powered electroflocculation harvesting system for nutraceutical coupled biodiesel production from marine microalga Chlorella vulgaris (NIOT-74)
}

\author{
Mary Leema $\mathrm{J}^{1}$, Thiruppathi Keppayan ${ }^{2}$, Magesh Peter ${ }^{1}$, Sreelatha $\mathrm{D}^{1}$, Kumar TS ${ }^{1}$, \\ Dharani Gopal $^{1}$, and Kirubagaran Ramalingam ${ }^{1}$ \\ ${ }^{1}$ National Institute of Ocean Technology \\ ${ }^{2}$ Department of Science and Technology
}

August 4, 2020

\begin{abstract}
Harvesting of microalgae is essentially the most energy intensive process in commercial algal culture ventures. Developing innovative, cost effective harvesting systems is of paramount need for commercial algal culture ventures. The study thus aimed at investigating the use of eco-friendly Solar Powered Electroflocculation (SPEF) coupled with battery for harvesting marine microalgae using aluminium electrodes. Optimization of various operating parameters like initial algal density, time of operation (5, 10, 15 and $30 \mathrm{~min}$ ), (initial biomass concentration 0.1, 0.5 and $1.0 \mathrm{gL}-1)$ and electrode distance (35, 55, 75 and $95 \mathrm{cms})$ were done using direct current (D.C). Best flocculation efficiency (91.31 $\pm 2.91 \%$ ) was obtained using a current density of 37.2 Acm-2, a voltage of $24 \mathrm{~V}$ for $15 \mathrm{~min}$ at an electrode distance of $95 \mathrm{~cm}$ and $\mathrm{pH}$ 8.0. The quality of the harvested biomass was ascertained in-terms of biochemical components using Fourier Transform Infrared spectroscopy, total lipid and pigment profile. Due to the low resistance of seawater the energy required for electroflocculation was as low as $0.223 \mathrm{kWh} / \mathrm{ton}$. The energy requirement for the electroflocculation system with or without solar power was also predicted. The results revealed SPEF can be developed as a potential alternative marine microalgal harvesting system for nutraceutical coupled biodiesel production.
\end{abstract}

\section{Hosted file}

Electroflocculation_paper_.docx available at https://authorea.com/users/344882/articles/ 473911-solar-powered-electroflocculation-harvesting-system-for-nutraceutical-coupledbiodiesel-production-from-marine-microalga-chlorella-vulgaris-niot-74

\section{Hosted file}

List of figures as on May 27.docx available at https://authorea.com/users/344882/articles/ 473911-solar-powered-electroflocculation-harvesting-system-for-nutraceutical-coupledbiodiesel-production-from-marine-microalga-chlorella-vulgaris-niot-74 